Revista de la Facultad de Medicina de la Universidad de lberoamérica

\title{
Articulo
}

\section{Historia de los Antimicrobianos}

\section{History of Antimicrobials}

\author{
Dr. Juan Ignacio Padilla Cuadra, Vicedecano de Medicina
}

\section{Resumen}

El desarrollo de los antimicrobianos marcó un hito en la medicina en tanto que permitió controlar las infecciones como una de las principales causas de muerte. Para conocer el desarrollo de los antimicrobianos, es necesario desarrollar la historia de cada uno de ellos o del grupo al que pertenece. Como otros logros de la medicina moderna, se notará que este involucra múltiples disciplinas, trabajo más allá del laboratorio e incluso, en algunos casos, la intervención de la suerte y hasta conflictos interpersonales.

\section{Descriptores}

Historia, antimicrobianos

\section{Abstract}

The development of antimicrobial agents was a milestone in medicine through controlling infection as one of the main causes of death. To know the history of antibiotics we will go through the development of each one of the most common agents or their chemical group. As in other fields of modern medicine, this history is about team work, research beyond the laboratory, and sometimes luck and conflicts.
Keywords

History, antimicrobials

\section{Introducción}

El desarrollo de los antimicrobianos marcó un hito en la medicina en tanto que permitió controlar las infecciones como una de las principales causas de muerte. El concepto de antibiótico, ahora más correctamente denominado como antimicrobiano, fue acuñado por Selman Waksman en 1941, y corresponde a sustancias que tiene la capacidad de inhibir el crecimiento de las bacterias e incluso causar su destrucción (1).

Para conocer el desarrollo de los antimicrobianos, es necesario repasar la historia de cada uno de ellos o del grupo al que pertenecen. Como otros logros de la medicina moderna, se notará que involucra múltiples disciplinas, así como trabajo más allá del laboratorio e incluso, en algunos casos, la intervención de la suerte y hasta conflictos interpersonales.

\section{Los primeros pasos}

Al igual que otros grandes descubrimientos médicos, el desarrollo de los antimicrobianos inició con el estudio de la naturaleza. Al 
principio, se reconoció que algunas sustancias producidas por ciertos microorganismos impedían el crecimiento de otras bacterias. No obstante, estas sustancias eran con frecuencia muy tóxicas para el uso en humanos lo cual retardó su aplicación clínica (por ejemplo: la piocianina producida por la Pseudomonas aeruginosa, causante de la coloración que contienen las infecciones por este germen). Otra orientación común, adoptada por los pioneros en este campo, fue deducir que si un colorante fijaba al germen, eventualmente podría, por esta selectividad, funcionar como un agente potencial para destruirlo. Bajo este principio, Paul Ehrlich desarrolló el salvarsán, un compuesto arsenical para el tratamiento de la sífilis (2).

\section{Descubrimiento de la Penicilina.}

En 1928, Alexander Fleming, un científico escocés demostró, accidentalmente, el efecto bactericida de un hongo, Penicillium, en un plato de cultivo (Figura 1). Según narra la historia, luego de un receso de vacaciones de dos semanas, Fleming notó en una placa de cultivo que el crecimiento de un hongo afectaba la proliferación de las colonias bacterianas. Es común identificar este descubrimiento como un accidente más que producto de la investigación metódica y como el mismo Fleming dijera "Uno a veces encuentra lo que no estaba buscando". Fleming había estado en la Primera Guerra Mundial y conocía las consecuencias de las infecciones por lo que se había dedicado a este campo. Por tanto, aunque parezca accidente, la sensibilidad y experiencia de este bacteriólogo, la situación particular de su laboratorio, un piso sobre el de micología (consecuentemente contaminación ambiental con hongos) y otras "casualidades", hacen que este descubrimiento no resulte tan accidental. Fleming, por el hongo de origen, denominó a la sustancia responsable de este efecto antibacteriano como penicilina (3-7). Aunque hay quienes aseguran que el científico costarricense Clodomiro Picado Twight habría obtenido resultados similares a
Fleming, no existe reporte científico definitivo que apoye esta afirmación. Limitaciones en el laboratorio de Fleming le obligaron a enviar muestras a otros científicos. Entre ellos, Howard Florey (farmacólogo australiano) y Ernst Chain (bioquímico alemán) de Oxford, realizaron la purificación bioquímica del producto. Florey y Chain son los que finalmente aíslan el agente antibiótico y comparten en 1945 el Premio Nobel con el escocés.

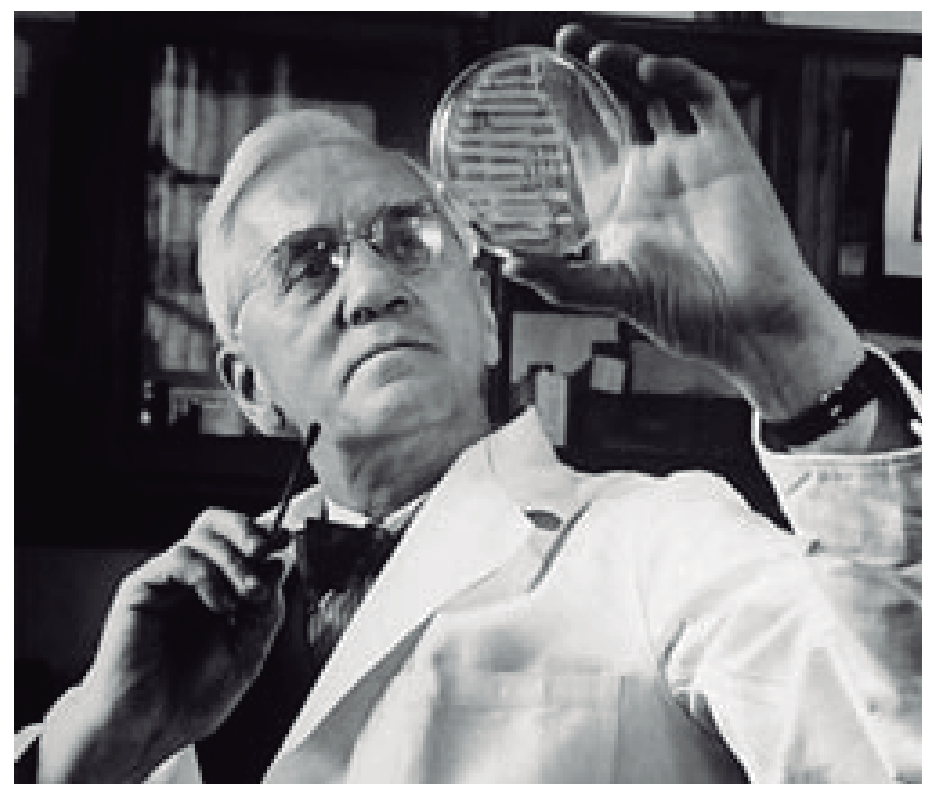

Figura 1. Alexander Fleming (1881-1955)

\section{Primer antibiótico sintético}

A fines de los años 20 del siglo pasado, la industria química alemana Farbenindustrie, dedicada a los colorantes sintéticos, inició la investigación de la aplicación de estos químicos con fines antibióticos. En 1932, uno de sus científicos, Gerhard Domagk demostró que el Prontosil Rubrum (un colorante rojo) protegía a conejos y ratones infectados por estafilococo y estreptococo (Figura 2). Esta sustancia resultó ser un derivado de las sulfonamidas y fue así como esta familia de antibióticos fueron los primeros agentes sintéticos con utilidad como antimicrobiano. Como dato anecdótico, la hija de Domagk sufrió de sepsis y fue tratada 
exitosamente con el producto. La empresa Farbenindustrie lo patentó y a Domagk le otorgaron el premio Nobel en Medicina en 1939 (8).

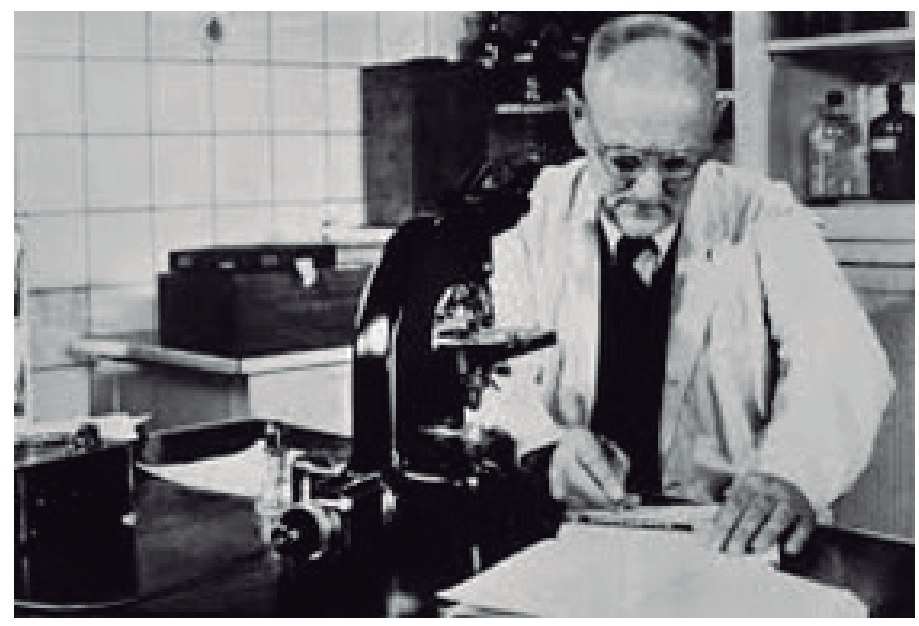

Figura 2. Gerhard Domagk (1895-1964),

La administración de la sulfadiazina fue primordial en la atención de pacientes quemados en el incendio en el centro nocturno Cocoanut en Boston, en donde su aplicación y uso de plasma fue decisivo (9). El incendio en este lugar obligó a la atención de decenas de pacientes quemados convirtiéndose en un hecho histórico no solo para los antibióticos, sino también para el manejo de fluidos de resucitación.

\section{Descubrimiento de la estreptomicina}

Cerca de 1940, el microbiólogo Selman Waksman (Figura 2), de la Universidad de Rutgers, Nueva Jersey, y René Dubós, empezaron estudios de suelos en busca de agentes antibióticos. Waksman demostró, mediante el análisis de los efectos antimicrobianos de agentes aislados del suelo, que el Streptomyces griseus generaba una sustancia con efectos antibióticos. El resultado fue conocido como estreptomicina que actualmente se utiliza en el tratamiento de la tuberculosis (10).
Ese antibiótico se agrupa actualmente entre los llamados aminoglucósidos, donde también se pueden ubicar la amikacina, gentamicina, neomicina y tobramicina. La neomicina se aisló en 1949 del Streptomyces fradiae, y la kanamicina del Streptomyces kanamyceticus en 1957. Por su parte, la gentamicina deriva del Micromonospora purpurea y fue descubierta en 1963. En 1976, derivada del Streptomyces tenebrarius, aparece la tobramicina que tiene especial actividad contra la Pseudomonas. Finalmente, se introduce la amikacina que es un agente semisintético y derivado de la kanamicina (11).

Actualmente, esa familia de antibióticos es de especial interés en el tratamiento de infecciones por gérmenes gram negativos y su toxicidad radica principalmente en $\mathrm{su}$ ototoxicidad $\mathrm{y}$ nefrotoxicidad.

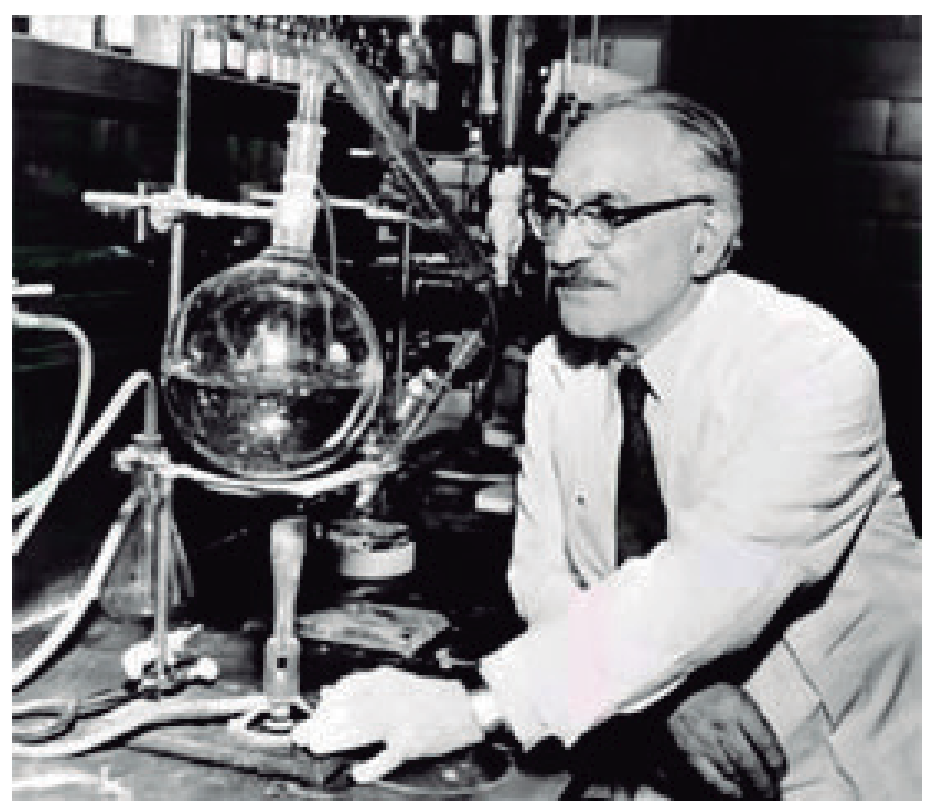

Figura 3. Selman Waksman. (1888 - 1973)

La controversia alrededor de la estreptomicina En 1945, Waksman había sido reconocido como el descubridor de la estreptomicina. No obstante, Albert Schatz (Figura 4), pupilo de tesis de Waksman y uno de sus asistentes, resintió no haber recibido mérito por todo su 
trabajo de laboratorio. Evidencia recabada posteriormente demostró que Schatz, quien estaba trabajando en su tesis doctoral, había sido el descubridor del antimicrobiano, al que asignó el nombre "experimento 11", pero no recibió premio alguno (12). El conflicto terminó en la corte, donde se acordó que Schatz fuera reconocido como codescubridor y tuviera también derecho a recibir ganancias por ese descubrimiento. Lamentablemente, acusar a Waksman porque lo excluyó de los méritos del descubrimiento, acabó con su Carrera, incluso debió desplazarse fuera de los Estados Unidos hasta Chile, donde laboró como docente. Por su parte, Waksman recibió el premio Nobel en Fisiología en 1952 y suele ser reconocido como el descubridor de la estreptomicina.

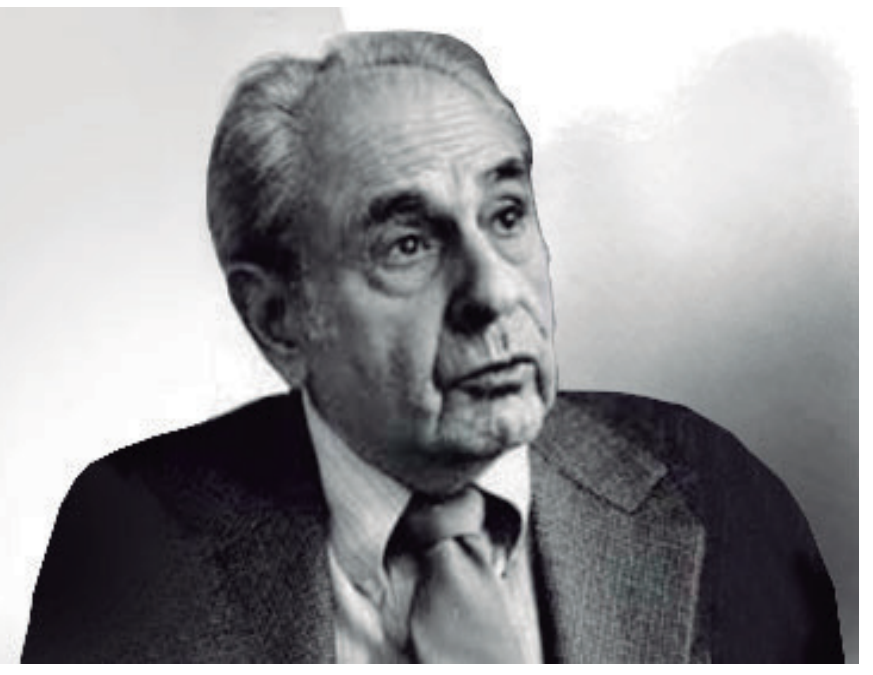

Figura 4. Albert Schatz . (1922 - 2005)

\section{Descubrimiento del cloranfenicol, la tetraciclina y los macrólidos}

Otro derivado de agentes aislados del suelo es la cloromicetina. Este agente, fue inicialmente extraído de muestra de suelo venezolano por Paul Burkholder de la Universidad de Yale. Su espectro incluye bacterias gram positivas $\mathrm{y}$ gram negativas y es conocido actualmente como cloranfenicol. Su uso se ha reducido debido a su toxicidad a nivel de médula ósea. En 1948, Benjamín Duggar aisló otra sustancia que ahora conocemos como clortetraciclina. Su espectro es similar al del cloranfenicol, pero menos tóxico (12).

A través de análisis de muestras de suelo, fue también descubierta la eritromicina, un macrólido, derivado del Streptomyces eritreus. La utilidad de este antimicrobiano radica principalmente en que por su espectro puede ser usado para sustituir la penicilina en casos de alergia.

Otro antibiótico sintético se obtuvo producto de la modificación química del núcleo de la penicilina y así nacieron la meticilina y la ampicilina. Este descubrimiento es de especial interés, pues permitió contar con un antibiótico contra estafilococo (13).

En 1970, se sintetizó la trimetoprima que se usa combinada con sulfametoxazol que combina mecanismos de acción diferentes y permite la inhibición secuencial de vías diferentes en el metabolismo bacteriano. Su uso actual es de importancia relevante en el tratamiento de la neumocistosis en pacientes inmunosuprimidos. Vancomicina

En 1952, un misionero radicado en Borneo envió a E. C. Kornfield de Laboratorios Eli Lilly, una muestra de suelo de la que se aísla al Streptomyces orientalis. Este germen se identificó como productor de una sustancia denominada "compuesto 05865" con propiedades antibióticas contra gérmenes gram-positivos especialmente el estafilococo resistente a penicilina. La purificación de la sustancia llevó a lo que conocemos como vancomicina derivado de la palabra en inglés vanquish que significa "vencer" (14).

\section{Origen de las Cefalosporinas}

En 1945, en las costas de Cerdeña, Giuseppe Brotzu estaba tratando de determinar un fenómeno de autopurificación que erradicaba naturalmente el agente de la tifoidea del agua (Figura 5). Estudiando muestra del desagüe, encontró el Cephalosporium acremonium, 


\section{(2) MEDICINA}

también

\section{denominado}

chrysogenum, que da origen a la familia de antibióticos llamados cefalosporinas (15). Dadas las limitaciones en Italia, el trabajo de Brotzu fue completo por Howard Florey en Oxford, Inglaterra, cuyas investigaciones demostraron que este hongo producía diferentes tipos de sustancias con efectos antimicrobianos.

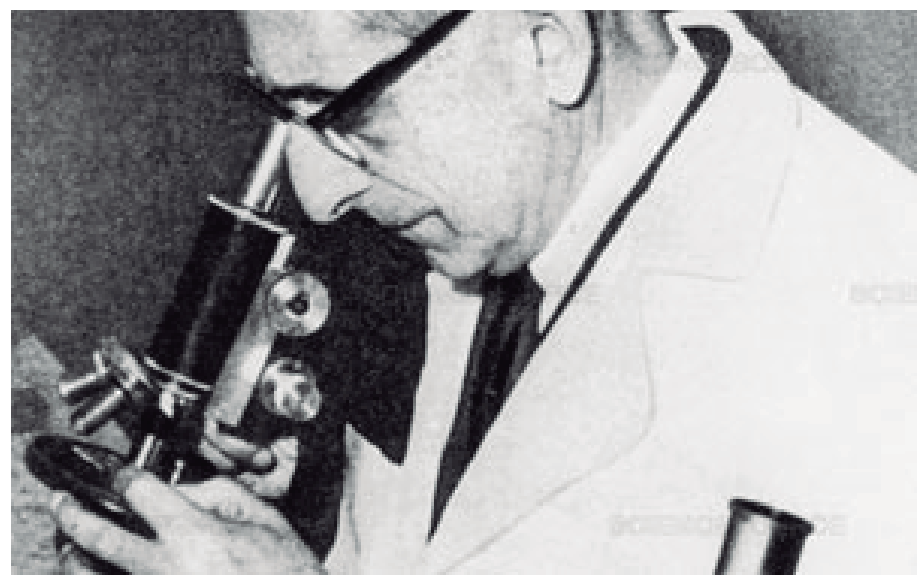

Figura 5. Giuseppe Brotzu (1895 - 1976)

\section{Agentes antituberculosos}

Aunque uno de los primeros agentes reconocido contra la tuberculosis fue la streptomicina, es importante reconocer el aporte de Jorgen Lehmann y Frederick Bernheim en el desarrollo de otro anti-tuberculoso, el ácido paraminosalicilico o PAS (Figura 6).

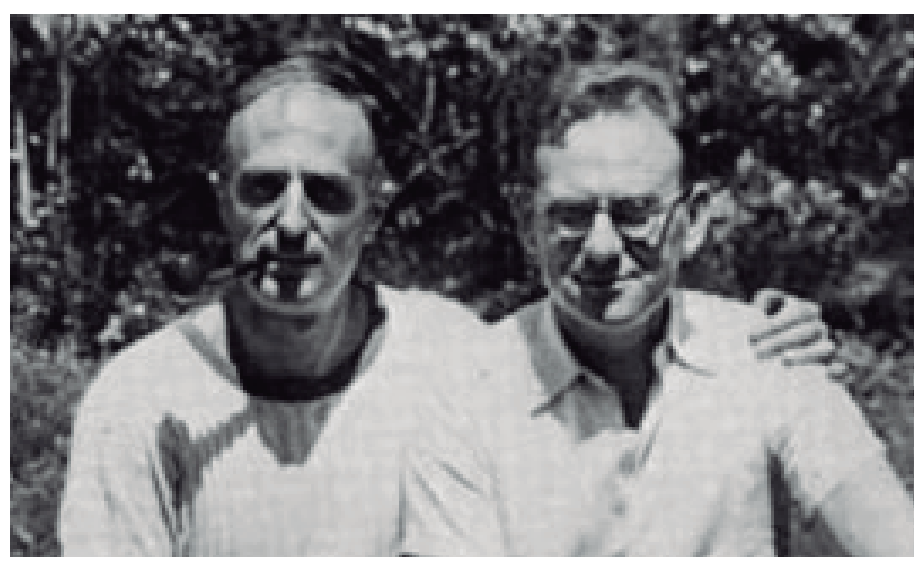

Figura 6. Jorgen Lehmann y Frederick Bernheimen 1949
En 1940, Frederick Bernheim de la Duke University de Carolina del Norte descubrió ciertos efectos metabólicos del ácido acetil salicílico sobre el agente causante de la tuberculosis. Por su parte, Jorgen Lehmann, al conocer sobre hallazgo dedujo que otro tipo de ácido de similar constitución química podia ser utilizado para aniquilar la bacteria Mycobacterium tuberculosis. Entonces, solicitó a la empresa Ferrosan la producción de derivados del ácido salicílico y resultó que el ácido para-aminosalicílico (PAS) mostraba efectos inhibtorios sobre el micobacterio de la tuberculosis.

Para 1951, mediante el trabajo conjunto entre las compañías Bayer, Squibb y Hoffmann-LaRoche, en los Estados Unidos se desarrolló la hidrazida de ácido isonicotínico, HAIN o major conocida como isoniazida. La cual demostró ser no solo eficaz contra la tuberculosis sino también poco tóxica.

La rifampicina, que pertenece a las llamadas rifamicinas, fue descubierta en 1957 en Italia. Es un derivado del suelo de un bosque de pinos de la Riviera Francesa estudiado por el laboratorio de Lepetit Pharmaceuticals en Milán. Este antibiótico fue usado por primera vez en 1966. Es de interés mencionar que su nombre deriva de una película de 1955 llamada Rififi que trata sobre unos asaltantes de joyas (Figura 7).

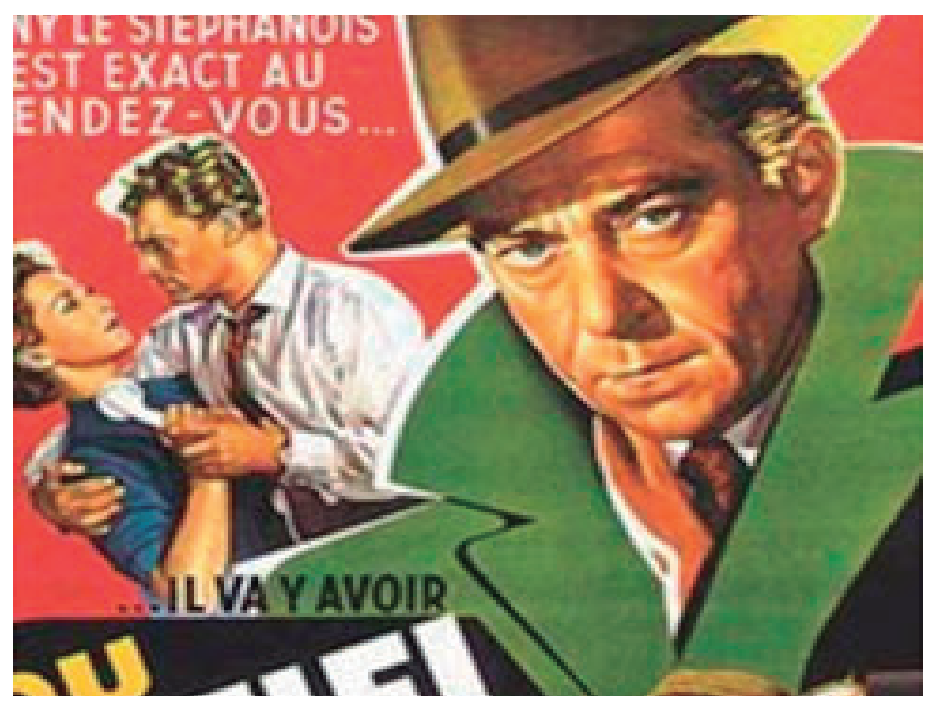

Figura 7. Origen del nombre de la rifampicina 


\section{Otros agentes}

Como en otros casos, las polimixinas, de las que son más comunes la polimixina B y la colistina, fueron derivadas en los años 40 del Bacillus polymyxa encontrado en muestras de suelo. Aunque su uso radicó principalmente a nivel ótico y oftálmico, la aparición de gérmenes resistentes ha obligado a su uso en infecciones sistémicas. Sobre el origen de los carbapenémicos, como el imipenem y el meropenem, se debe reconocer que nacieron de la necesidad de tratar la proliferación de bacterias resistentes. Originalmente, se derivan del Streptomyces catleya, un agente denominado tienamicina, que es la base de todos los carbapenémicos y muestra efectos antibacterianos contra un amplio espectro de gérmenes, lo cual fue reconocido desde 1976.

En los años 60, apareció la primera quinolona, un subproducto de la cloroquina, ácido 7 -cloro-l-etil-1,

4-dihidro-4-oxoquinolina3-carboxílico (16). Su historia es un poco ambigua y no es posible determinar claramente quién la descubrió, probablemente por razones de patentes industriales. El agente original derivó del ácido nalidixico con efectos particularmente satisfactorios en infecciones urinarias. Este producto tenía muy poca absorción oral. Posteriormente, se desarrollaron la ciprofloxacina, norfloxacina, levofloxacina y otras. Una de sus versiones, la temofloxacina fue retirada por causar una reacción sistémica severa.

Un caso curioso que merece mención es el metronidazole. Este fármaco fue desarrollado por laboratorios Rhone-Poulenc en Francia a partir de extractos de Streptomyces spp., para el tratamiento de la Trichomonas vaginalis. Posteriormente, mostró ser eficaz en el manejo de la Entamoeba histolytica (17 ). Por accidente, en los años 70, se demostró la curación simultánea de tricomoniasis y de una infección a nivel gingival. Esto mostró la utilidad del agente en el manejo de infecciones por anaerobios incluyendo el Clostridium difficile.

\section{Conclusiones}

La historia de los agentes antimicrobianos muestra como su desarrollo ha sido a través de esfuerzos en diversos centros alrededor del mundo, en ocasiones producto de situaciones catalogadas como accidentes (Tabla 1). Es frecuente que los antibióticos se originen a partir de productos derivados de otras bacterias y hongos, pero otros son sintéticos. La aparición de gérmenes resistentes a los antimicrobianos que existen obliga a repetir el camino histórico con el fin de encontrar nuevos agentes de la misma manera que otros pioneros lo hicieron.

Tabla 1. Cronología del Descubrimiento de Principales Antibióticos
Descubrimiento

Penicilina

Prontosil

(origen de las sulfonamidas)

Estreptomicina

Cefalosporinas

Cloranfenicol

Eritromicina

Vancomicina

Rifampicina

Meticilina

Nalidíxico

Trimetroprima
Año

1929

1932

1943

1945

1947

1952

1956

1957

1960

1962

1970 


\section{Referencias}

1. Waksman S. Definition of antibiotics. Antibiotic Med Clin Ther. 1956; 2(2):82-6.

2. Gensini GF, conti aa, Lippi D. the contributions of Paul Ehrlich to infectious disease. J infect. 2007; 54(3):221-4.

3. Fleming A. 1929.On the antibacterial action of cultures of a penicillium, with special reference to their use in the isolation of $\mathrm{B}$. influenzae. Br J Exp Pathol 10: 226-236.

4. Bentley R. the development of penicillin: genesis of a famous antibiotic. Perspect Biol Med. 2005; 48(3):444-52.

5. Wennergren G, Lagercrantz h. "One sometimes finds what one is not looking for" (sir alexander Fleming): the most important medical discovery of the 20th century. Acta Paediatr. 2007; 96(1):141-4.

6. Fleming A. The discovery of penicillin. $\mathrm{Br}$ Med Bull. 1944; 2(1):4-5.

7. Fielding J. History of Penicillin. Lancet. 1980; 1(8158):43-4.

8. Aver G, Mottin V, Kreuz O, Suyenaga E. Genesis of pharmaceuticals: from prontosil rubrum to antipsychotics - a history of sulfa drugs from the perspective of medicinal chemistry. IJRPC 2017, 7(3), 306-319.

9. Stewart CL. The fire at Cocoanut Grove. J Burn Care Res. 2015; 36(1):232-5.

10. Waksman SA. Selman Abraham Waksman, Ph.D. 22 July 1888-16 August 1973. Who "discovered" streptomycin? Ann Intern Med. 1973; 79(5):646.

11. Belloso W. Historia de los antibióticos. Revista Hospital Italiano 2009; 29 (2): 102-110. 12. Pringle P. Experiment Eleven: Dark Secrets
Behind the Discovery of a Wonder Drug 2013, Bloomsbury USA

13. Rolinson GN. Forty years of betalactam research. J Antimicrob Chemother. 1998; 41(6):589-603.

14. Levine D. Vancomycin: A HistoryClinical Infectious Diseases 2006; 42:S5-12

15. Bo G. Giuseppe Brotzu and the discovery of cephalosporins. Clin Microbiol Infect 2000: 6 ( Supplement 3): 6-8.

16. Bisacchi G. Origins of the Quinolone Class of Antibacterials: An Expanded "Discovery Story” J. Med. Chem. 2015, 58, 4874-4882

17. Samuelson J. Why metronidazole is active against both bacteria and parasites. Antimicrob Agents Chemother. 1999 Jul; 43(7):1533-41. 